\title{
Investigation of the effects of household processing on the reduction rate of chlorpyrifos, metalaxyl and diazinon residues in orange fruit
}

\author{
E. El-Sayed ${ }^{*}$, H. Hassan ${ }^{2}$, A. Abd El-Raouf ${ }^{3}$ and S.N. Salman ${ }^{2}$
}

Summary The effect of the household processing on the reduction rate of chlorpyrifos, metalaxyl and diazinon residues in contaminated oranges has been investigated and the processing factors were determined. The evaluation included validation parameters, matrix effect (ME \%), reduction behavior and processing factors (PFs). Validation parameters were successfully applied; the three pesticides showed satisfactory recovery (70-120\%) and precision (relative standard deviation - RSD $<20 \%$ ); they also exhibited no matrix effect. The most effective process in the pesticide residues reduction was juicing, followed by pulping while the washing process was less efficient in removing all pesticide residues; sonication showed a high reduction rate with both chlorpyrifos and diazinon. The processing factors (PFs) were generally less than one which indicates that all processes can reduce pesticide residues in oranges. The results could guide the safe and reasonable use of chlorpyrifos, diazinon, and metalaxyl. These processes contribute substantially to reduce consumer exposure to pesticide residues in oranges.

Additional keywords: GC/MS, QuEChERS, matrix effect, oranges, pesticides, Processing Factor

\section{Introduction}

Oranges are among the fruits most widely accepted as they are an excellent source of vitamin C, fiber, and antioxidants (Barrose et al., 2012). Analysis of 141 pesticide residues in 31 orange samples from Egypt by Malhat et al. (2017) showed $66.7 \%$ of them being contaminated with 8 different pesticide residues, including fenpropathrin and chlorpyrifos, which were also detected in this work.

Chlorpyrifos is an organophosphorus insecticide and acaricide that is widely used to combat pests infesting citrus fruits (European Food Safety Authority, 2011; Jardim and Caldas, 2012). Two organophosphorus pesticides, chlorpyrifos (5.3\%) and diazinon (10.5\%) were found by Iñigo-Nuñez et al. (2010) in 19 orange juice samples from mar-

\footnotetext{
Department of Dairy Science, Faculty of Agriculture, Cairo University, Egypt.

${ }^{2}$ Department of Laser Application in Agriculture, National Institute of Laser Enhanced Sciences (NILES), Cairo University, Egypt.

${ }^{3}$ Agricultural Engineering Research Institute, Agricultural Research Center, Egypt.

* Corresponding author: elham.must@gmail.com

ORCID ID https://orcid.org/0000-0001-7025-0695
}

kets in Madrid (Spain). Knezevic, et al. (2012) studied 103 pesticides (including isomers) in 105 commercial orange samples in Croatia from 2007 to 2009, and diazinon residues were found up to levels of $0.28 \mathrm{mg} \cdot \mathrm{kg}^{-1}$.

Effects of food processing on pesticide residues have been reviewed comprehensively over the last decade (GonzálezRodríguez et al., 2011) and the literature review shows that most household processing treatments lead to considerable reductions in residue levels in the prepared food, particularly through washing and peeling, fermentation, refrigeration singly or in combination. The behavior of residues in storage and processing can be rationalized in terms of the physico-chemical properties of the pesticide and the nature of the process (Vinita et al., 2013).

Bonnechere et al. (2012) studied the processing factors of several pesticides and degradation products in carrots by household and industrial processing, such as washing, peeling, blanching, microwave cooking, pasteurization and sterilization. The levels of six pesticide residues and eight associated degradation products were quantified. The washing step allowed decreasing 
the concentration of residues for all pesticides up to $\sim 90 \%$. It was the most effective step to remove pesticide residues from carrots. The second process, peeling, resulted in a reduction comparable to washing. The blanching step, combining heat with a large quantity of water, enhanced the elimination of residues (maximum 50\%). After cutting and washing, the residual concentrations were below 5 ppb.

Processing factors (PFs) are the ratio of residue concentrations after processing to those in the raw commodity. PF values greater than 1 indicate an increase in pesticide residue concentrations during processing; PF values less than 1 indicate decreases (Ramezani and Shahriari, 2014). PFs depend on both the crop and the physicochemical properties of pesticides (GonzálezRodríguez et al., 2011), especially water solubility and the water-octanol partition coefficient (Kow). Pesticides with high water solubility and with low Kow and Koc are mostly transferred to the juice, but those with low solubility and high Kow and Koc are retained on some fruit skins. Peeling and storage were found to be two important processing procedures that may remarkably reduce non-systemic pesticide residues in some fruits and vegetables (Ramezani and Shahriari, 2014; Jiang et al., 2013).

Validation parameters such as sensitivity, linearity, specificity, trueness, precision, limit of detection (LOD), limit of quantitation (LOQ), and matrix effect are commonly evaluated in pesticide residues determination. Chromatographic techniques established that matrix effect is significant when higher than $\pm 20 \%$ (Sherif et al., 2016; SANTE/11813/2017). In recent years, it has been essential to use matrix-matched calibration in routine procedure for the analysis of pesticides in food by chromatographic methods to avoid an error caused by the presence of matrix effect (Kwon et al. 2012). In previous study, in which the validation of the GC-MS method was the main focus, QuEChERS was employed as a sample preparation technique for the determination of chlorpyrifos and metalaxyl residues in to- matoes matrices (Hassan et al., 2019).

Lozowicka et al. (2016) determined the processing factor (PF) for 16 pesticides processing techniques in strawberries. Washing with ozonized water was demonstrated to be a more effective reduction strategy, displaying percentage ranges from 36.1 to $75.1 \%$ compared to washing with tap water (respective ranges fluctuated from 19.8 to $68.1 \%)$. Boiling decreased the residues of the most compounds with reductions ranging from 42.8 to $92.9 \%$. Ultrasonic cleaning lowered residues for all analyzed pesticides with removal above $90 \%$. According to Bajwa and Sandhu (2014), ultrasonic cleaning and boiling were the most effective treatments for the reduction of 16 pesticide residues in raw strawberries, resulting in a lower health risk exposure.

The aim of the present study was to evaluate validation parameters, matrix effect and the impact of several processing techniques on the reduction rate of chlorpyrifos, metalaxyl and diazinon pesticide residues on orange fruits.

\section{Materials and Methods}

Organic Oranges were bought from $\mathrm{BIO}$ COMPANY ${ }^{\oplus}, \mathrm{GmbH}$, Rheinstrasse, Berlin, Germany. Commercial plant protection products were used in artificial contamination of oranges: Ridomil 72 (8\% metalaxyl), Helban 48 (48\% chlorpyrifos), Basudin 60 EC (diazinon) were purchased from Al-Mukhtar for pesticides and chemicals, Monufia Governorate, Egypt. Metalaxyl $(1000 \mu \mathrm{g} / \mathrm{ml})$ dissolved in acetone was supplied from SPEXCertiPrep, New Jersey, USA. Chlorpyrifos $1000 \mu \mathrm{g} / \mathrm{mL}$ in methanol, Diazinon $1000 \mu \mathrm{g} /$ $\mathrm{mL}$ in methanol were supplied from Restek, Pennsylvania, USA. Acetonitrile (HPLC grade, assay 99.9\%) was obtained from Merck KGaA, Darmstadt, Germany. Hydrogen peroxide solution $31 \%$ (Ultrapure), anhydrous Sodium bicarbonate and acetic acid were purchased from Sigma-Aldrich, St. Louis, USA. The QuEChERS kit consisted of extraction packets and dispersive SPE kit suited to 
the orange matrix, were purchased from $\mathrm{Ag}$ ilent Technologies, California, USA.

\section{Instruments}

The equipment used in processing and sample preparations were: a laboratory Blender (Waring, Stamford, USA), an analytical balance, model ME 104 (Mettler Toledo, Greifensee, Switzerland), a Vortex-mixer, (VELP scientific, Usmate Velate, Italy), centrifuge (BOECO, Hamburg, Germany), and Ultrasonic Tabletop Cleaner, model P 230 (CREST Ultrasonics, Penang, Malaysia).

\section{Extraction and clean-up}

The samples were treated according to the QuEChERS methodology [EN 15662: (2008)].

\section{GC-MS analysis}

Qualitative and quantitative determination of pesticide residues were performed on a 7890B gas chromatograph coupled to an Agilent 5977A mass detector (Agilent Technologies, Wilmington, USA). The chromatographic analytical conditions are shown in Table 1.

\section{Method validation and matrix effect}

The proposed method was validated following the European Commission guideline (SANTE/11813/2017). The parameters assessed were selectivity, specificity, linearity, LOD, LOQ, precision, recovery (trueness) and matrix effect.

The linearity was studied during the construction of the analytical curves obtained using analytical solutions of the mixture of the pesticides prepared in pure solvent and the extract of the orange matrix in the concentration range from 0.001 to $2 \mathrm{mg} / \mathrm{L}$. The studies to evaluate the recovery of the pesticides were made in orange samples devoid of pesticides residues, which were fortified five times with an analytical solution containing the pesticides under study, at two different concentration levels. The study of repeatability of the instrument was evaluated with five injections in the chromatographic system for each level of concentration of the analytical solutions in pure solvent and in the extract of the matrix.

LODs and LOQs have been calculated based on two analytical parameters: the residual standard deviation of the matrix cal-

Table 1. GC/MS instrumental and analytical condition for analysis of metalaxyl, chlorpyrifos and diazinon residues.

\begin{tabular}{|c|c|}
\hline Column & $\begin{array}{l}\text { Zebron ZB-5MS Crossbond ( } 30 \mathrm{~m}, 0.25 \mathrm{~mm} \text { internal diameter, } 0.25 \mathrm{~mm} \\
\text { film thickness) from Phenomenex }{ }^{\circledR} \text {, Torrance, CA, USA. }\end{array}$ \\
\hline Inlet & Multimode inlet (MMI) operated in splitless mode \\
\hline Inlet liner & $\begin{array}{l}\text { An Agilent ultra-inert splitlesss single taper liner with glass wool }(\mathrm{p} / \mathrm{n} \\
5190-2293)^{*}\end{array}$ \\
\hline Carrier gas & Helium with purity grade 6 for $9 \mathrm{~s}$ \\
\hline Flow rate & $1 \mathrm{~mL} / \mathrm{min}$ (constant flow mode) \\
\hline Inlet temperature & $250^{\circ} \mathrm{C}$ \\
\hline Injection volume & $2 \mu \mathrm{L}$ \\
\hline Purge flow to split vent & $50 \mathrm{~mL} / \mathrm{min}$ at $0.75 \mathrm{~min}$ \\
\hline Oven temperature program & $60^{\circ} \mathrm{C}(1 \mathrm{~min}), 20^{\circ} \mathrm{C} / \mathrm{min}$ to $170^{\circ} \mathrm{C}(0 \mathrm{~min}), 5^{\circ} \mathrm{C} / \mathrm{min}$ to $285^{\circ} \mathrm{C}$ \\
\hline Mass detector & operated in electron impact (EI) ionization mode at $70 \mathrm{eV}$. \\
\hline Scan mode & $\begin{array}{l}\text { mass spectra for stock solutions of metalaxyl, chlorpyrifos and diazi- } \\
\text { non was collected at the rate of } 1.5 \text { scans/s over the mass range }(\mathrm{m} / \mathrm{z}) \\
\text { of } 40-550\end{array}$ \\
\hline Quantitative measurement & was carried out at Selected ion monitoring SIM mode ${ }^{* *}$ \\
\hline $\begin{array}{l}\text { The temperatures of the transfer line, } \\
\text { ion source, quadrupole }\end{array}$ & $285^{\circ} \mathrm{C}, 250^{\circ} \mathrm{C}, 150^{\circ} \mathrm{C}$ \\
\hline
\end{tabular}

*Zhao and Mao (2011); Zhao (2013). **Refer to Table 3 for settings in detail 
ibration curve $(\sigma)$ and the slope of the calibration curve as in Eq (1) \&Eq (2) (Ellison et al., 2000).

$$
\begin{array}{ll}
\mathrm{LOD}=3.3 \sigma / \text { slope } & \mathrm{Eq}(1) \\
\mathrm{LOQ}=10 \sigma / \text { slope } & \mathrm{Eq}(2)
\end{array}
$$

The precision of the method was expressed as the relative standard deviation (RSD) for repeatability of 5 replicates of spiked blank orange samples (raw, juice, and pulp) at two concentration levels of 0.03 and $0.5 \mathrm{mg} / \mathrm{kg}$ for metalaxyl, 0.01 and 0.5 $\mathrm{mg} / \mathrm{kg}$ for chlorpyrifos and diazinon. The percentage recoveries ( $\mathrm{R} \%$ ) for chlorpyrifos, diazinon and metalaxyl were calculated according to the European Commission guideline (SANTE/11813/2017). Acceptable mean recoveries are those within the range of $70-120 \%$.

Matrix effect (ME \%) was determined by comparing the slopes obtained from solvent calibration and matrix-matched calibration curves. ME \% was calculated according to Guedes et al. (2015):

$\mathrm{ME}=\left[1-\left(\frac{\text { stope of solvent }}{\text { stope of matrix calibration }}\right)\right] * 100 \mathrm{Eq}$ (3)

\section{Preparation of contaminated samples}

Orange fruits were contaminated by immersion into the pesticide's solution. Organic oranges were manually washed in distilled water and dried with filter paper, then dipped into a dipping solution containing $0.5 \mathrm{~g}$ Ridomil WP 72 WP, $2 \mathrm{ml}$ of Helban 48 EC and $2 \mathrm{ml}$ Basudin 60 EC per liter of water to obtain a sufficient quantity of suspension. The samples were immersed for one hour until the pesticide residue levels did not increase. The contaminated oranges were air dried for $24 \mathrm{~h}$ at room temperature before processing (Hassan et al., 2019).

\section{Processing treatments}

Processing treatments for removal of pesticide residues from contaminated oranges samples are illustrated in Table 2. After each process, three representative replicates were taken from each treatment for residue analysis. After each experiment, the samples were extracted immediately and analyzed, the percentages of reduction were calculated and compared with control.

\section{Processing factors}

Processing factors (PFs) were calculated for all transformation steps by a ratio between the pesticide residue concentration ( $\mathrm{mg} \mathrm{kg}^{-1}$ ) in the processed commodity and the pesticide residue concentration $(\mathrm{mg}$ $\mathrm{kg}^{-1}$ ) in the raw, non-processed commodity. If a PF is lower than one, it indicates the reduction of a pesticide, while if higher than 1 , it indicates a concentration in regulatory practice, regardless of changes in volume or weight for the processed food. (Aurore et al., 2012; Bonnechère et al., 2012). PFs were cal-

Table 2. Processing treatments for removal of pesticide residues from contaminated oranges samples.

\begin{tabular}{l|l}
\hline Treatment & Description \\
\hline Peeling \& Juicing & $\begin{array}{l}\text { Group 1: Pulp } \\
\text { Group 2: Juice } \\
\text { Washing }\end{array}$ \\
& $\begin{array}{l}\text { Group 1: washing contaminated oranges with tap water for } 10 \mathrm{~min} \\
\text { Group 2: washing with } 10 \% \text { sodium bicarbonate solution (w/v) for } 10 \mathrm{~min} \\
\text { Group 3: washing with } 4 \% \text { acetic acid solution(v/v) for } 10 \mathrm{~min} \\
\text { Group 4: washing with } 1 \% \mathrm{H}_{2} \mathrm{O}_{2} \text { solution }(\mathrm{v} / \mathrm{v})\end{array}$ \\
$\begin{array}{l}\text { Sonication in ultrasonic bath } \\
\text { (45 kHz) filled with distilled } \\
\text { water }\end{array}$ & $\begin{array}{l}\text { Group 1(UB1): sonication for } 15 \text { min } \\
\text { Group 3(UB3): sonication for } 60 \mathrm{~min}\end{array}$ \\
\hline
\end{tabular}


culated with the following equation (Timme and Walz-Tylla, 2004):

$\mathrm{PFs}=\frac{\text { Residues in processed product }(\mathrm{mg} / \mathrm{kg})}{\text { Residues in raw agricultural commodity }(\mathrm{mg} / \mathrm{kg})} \quad \mathrm{Eq}(4)$

\section{Results and Discussion}

\section{Optimization of separation conditions using GC/MS}

The presence of matrix interferences from the orange fruit samples was evaluated by monitoring the specific ions for each pesticide at the retention time interval expected for their elution (Table 3). For qualitative analysis a full scan mass spectrum range form $40-550(\mathrm{~m} / \mathrm{z}$ ) was applied (PanoFarias et al., 2017).

For quantitative pesticide analysis, selected ion monitoring (SIM) mode was used and analyte peaks from both product ions in the extracted ion chromatograms fully overlapped. The monitored ions for each compound were the $\mathrm{m} / \mathrm{z} 137,152,153,304$ for diazinon, $\mathrm{m} / \mathrm{z} 132,105,142,192,297$ for metalaxyl and m/z 197, 199, 314 for chlorpyrifos. Pesticides were also identified on the basis of their retention time consistency with the ones acquired by standard and spiked extract solutions injections (chlo- rpyrifos $14.63 \mathrm{~min}$, diazinon $11.72 \mathrm{~min}$ and metalaxyl $13.59 \mathrm{~min})$.

\section{Analytical method validation parame- ters}

Linearity in solvent and orange matrix extract for metalaxyl, diazinon and chlorpyrifos (Table 4) was acceptable, as indicated by the values of regression coefficient $\left(r^{2}\right)$ that were $>0.99$ for all compounds in solvent, and in the matrix (De Sousa et al., 2012; Domínguez et al., 2014). According to the European Commission guideline SANTE/11813/2017, the acceptable RSD should be $\leq 20 \%$, where the fit of calibration inspected by calculation of the residuals avoids over-reliance on the correlation coefficient. The ME \% (suppression or enhancement) is the signal increase or loss of an analyte in matrix standard solution compared to a matrix-free one. For metalaxyl, chlorpyrifos and diazinon ME \% were -14.16, -12.1, -5.48 , respectively, categorized by Ferrer et al. (2011) as no matrix effect (Table 4). These results were in agreement with the findings reported by Ferrer et al. 2011 and Chawla et al. (2017).

The analytical method was used to evaluate recovery, precision, LODs and LOQs for determining metalaxyl, chlorpyrifos and di-

Table 3. Optimized MS Parameters of pesticides metalaxyl, chlorpyrifos, diazinon.

\begin{tabular}{l|c|c|c}
\hline Compound & $\begin{array}{c}\text { Diagnostic ions } \\
(\mathrm{m} / \mathrm{z})\end{array}$ & $\begin{array}{c}\text { Quantification ions } \\
(\mathrm{m} / \mathrm{z})\end{array}$ & $\begin{array}{c}\text { Retention time } \\
(\mathrm{min})\end{array}$ \\
\hline Metalaxyl & $132,105,192,279,206.1$ & 206.1 & $13.59 \pm 0.2$ \\
Chloropyrifos & $197,199,314$ & 314 & $14.63 \pm 0.2$ \\
Diazinon & $137,152,153,304$ & 304.1 & $11.71 \pm 0.2$ \\
\hline
\end{tabular}

Table 4. Matrix effect (ME \%) and linearity parameters in solvent and orange matrix extract for metalaxyl, diazinon and chlorpyrifos.

\begin{tabular}{l|c|c|c|c|c|c}
\hline \multirow{2}{*}{ Pesticide } & \multirow{2}{*}{$\begin{array}{c}\text { Linear range } \\
(\mathrm{mg} / \mathrm{kg})\end{array}$} & \multicolumn{2}{|c|}{ Solvent } & \multicolumn{3}{c}{ Matrix match orange } \\
\cline { 3 - 7 } & $0.03: 2$ & 342610 & 0.9981 & 300110 & 0.9979 & -14.16 \\
\hline Metalaxyl & $0.01: 2$ & 432881 & 0.9994 & 386196 & 0.9990 & -12.1 \\
Chlorpyrifos & $0.01: 2$ & 425793 & 0.9992 & 403666 & 0.9991 & -5.48 \\
Diazinon & & & & & & $r^{2}$ \\
\hline
\end{tabular}

Regression coefficient $\left(r^{2}\right)$ 
azinon residues in orange (Table 5). The obtained LODs and LOQs were based on matrix matched calibration data at low levels of concentrations as we spike blank orange matrix with pesticides at conc. levels 5, 10, 25, $50,100 \mathrm{mg} / \mathrm{kg}$ each in 5 replicates. Subjected to all the method preparation and injection steps, we found the detector response correlating to its concentration (peak area), calculating the average using data analysis function to calculate LOQ and LOD. The LOD and LOQ for metalaxyl were $0.01 \mathrm{mg} /$ $\mathrm{kg}$, and $0.03 \mathrm{mg} / \mathrm{kg}$ respectively, while LOD and LOQ for both chlorpyrifos and diazinon were $0.003 \mathrm{mg} / \mathrm{kg}$, and $0.009 \mathrm{mg} / \mathrm{kg}$, respectively.

Before pesticide residue analysis, recovery experiments were carried out on orange fruit, orange juice, and orange pulp. Recovery and precision data are shown in Tables
5 and 6 . Residue analysis of the recovery experiments showed that mean recovery percentages were highest in orange fruit than in orange juice and in orange pulp for all pesticides. Also, chlorpyrifos had the highest recovery rates and the lowest RSD \% than all pesticides. The recovery percentage (70-120\%) and precision of all pesticide residue analyses (RSD $\leq 20 \%$ ) were within the satisfactory limits recommended by the EC guideline SANTE/11813/2017.

Quantification using calibration was performed by means of calibration curves using the peak area of the most intense transition of metalaxyl ( $\mathrm{m} / \mathrm{z} 220)$. Calibration plots were linear, with regression coefficients greater than 0.99 . The LOQ of the method were $17 \mu_{\mathrm{g} \mathrm{kg}} \mathrm{k}^{-1}$ while the LOD were $8.5 \mu \mathrm{g}$ $\mathrm{kg}-1$.

Table 5. Validation parameters for metalaxyl, diazinon and chlorpyrifos in orange fruit.

\begin{tabular}{|c|c|c|c|c|c|c|c|c|c|c|}
\hline \multirow{9}{*}{$\begin{array}{l}0 \\
\text { ర్ } \\
\frac{1}{0} \\
\text { to }\end{array}$} & \multirow{3}{*}{ Pesticide } & \multirow{3}{*}{ LOD $^{a}$} & \multirow{3}{*}{$\mathrm{LOQ}^{\mathrm{b}}$} & \multicolumn{7}{|c|}{ Recovery and precision $\left({ }^{*} n=5\right)$} \\
\hline & & & & \multirow{2}{*}{ FLC } & \multicolumn{2}{|c|}{ Whole fruit* } & \multicolumn{2}{|c|}{ Juice* } & \multicolumn{2}{|c|}{ Pulp* } \\
\hline & & & & & $\mathrm{R} \%^{\mathrm{d}}$ & RSD\% ${ }^{\mathrm{e}}$ & $\mathrm{R} \%$ & RSD\% & $\mathrm{R} \%$ & RSD $\%$ \\
\hline & \multirow{2}{*}{ Metalaxyl } & \multirow{2}{*}{0.01} & \multirow{2}{*}{0.03} & 0.03 & 108.5 & 10.8 & 89.6 & 11.1 & 99.5 & 10.5 \\
\hline & & & & 0.5 & 97.7 & 8.6 & 88.3 & 8.3 & 94.6 & 9.8 \\
\hline & \multirow{2}{*}{ Chlorpyrifos } & \multirow{2}{*}{0.003} & \multirow{2}{*}{0.009} & 0.01 & 114.3 & 2.7 & 112.0 & 4.1 & 106.8 & 3.6 \\
\hline & & & & 0.5 & 100.2 & 3.5 & 107.0 & 2.2 & 103.0 & 2.8 \\
\hline & \multirow{2}{*}{ Diazinon } & \multirow{2}{*}{0.003} & \multirow{2}{*}{0.009} & 0.01 & 99.5 & 8.3 & 111.4 & 5.8 & 106.3 & 7.9 \\
\hline & & & & 0.5 & 97.0 & 6.4 & 100.5 & 2.9 & 102.2 & 4.8 \\
\hline
\end{tabular}

aLimit of detection $(\mathrm{mg} / \mathrm{kg})$, b ${ }^{2}$ imit of quantification $(\mathrm{mg} / \mathrm{kg})$, 'Fortification Level,

$\mathrm{R}^{\mathrm{d}} \%$ : Percentage recovery $=\mathrm{CE} / \mathrm{CM} \times 100$;

$\mathrm{CE}$ : the experimental concentration, $\mathrm{CM}$ : the spiked concentration

eRelative Standard Deviation, ${ }^{*}$ : no of replicates

Table 6. Repeatability and Reproducibility (precision) expressed as \%RSD of peak areas for spiked samples.

\begin{tabular}{l|c|c|c|c}
\hline & \multicolumn{2}{|c|}{ Repeatability } & \multicolumn{2}{c}{ Reproducibility } \\
\hline & Level 1 & Level 2 & Level 1 & Level 2 \\
\hline Diazinon & 1.51 & 1.36 & 8.00 & 9.07 \\
Chlorpyrifos & 1.78 & 1.82 & 3.66 & 5.12 \\
Metalaxyl & 3.02 & 2.71 & 10.00 & 11.0 \\
\hline
\end{tabular}

Level $1=0.01 \mathrm{mg} / \mathrm{kg}$ for diazinon and chlorpyrifos, $0.03 \mathrm{mg} / \mathrm{kg}$ for metalaxyl;

Level $2=0.1 \mathrm{mg} / \mathrm{kg}$ for all pesticides under study 
Physicochemical properties of metalaxyl, diazinon and chlorpyrifos

The behavior of pesticide residues in processing can be rationalized in terms of the physico-chemical properties of the pesticide and the nature of the process (Vidisha and Jaswinder, 2013). Table 7 shows the physicochemical properties of metalaxyl, diazinon and chlorpyrifos. Both diazinon and chlorpyrifos are non-systemic, while metalaxyl is systemic, thus it is absorbed by the plant surface and enters the plant transport system.

Regarding water solubility, it has been shown (Table 7) that pesticides with high water solubility and with low Kow and Koc are mostly transferred to the juice. Those with low solubility and high Kow and Koc are retained on the fruit skin. Peeling and storage were found to be two essential processing procedures that may remarkably reduce non-systemic pesticide residues in some fruits and vegetables (Ling et al., 2011).

\section{Effect of various household processes}

The study of the reduction of pesticides during household processes of orange fruit allows calculating the PFs for the tested pesticides, which are necessary to refine the risk assessment of these frequently detected pesticides.

Table 8 shows the reduction of the first treatment by household processes (raw orange, orange juice, and orange pulp) on metalaxyl, chlorpyrifos and diazinon residues. The juicing process was the most ef- fective process in removing all pesticides; metalaxyl residues were reduced by $95 \%$ in orange juice and $93 \%$ in orange pulp, while chlorpyrifos and diazinon residues were reduced by $98 \%, 97 \%$ in orange juice and $90 \%$, $86 \%$ in orange pulp, respectively.

Washing showed the less efficient removal of all pesticide residues. The residues of metalaxyl after washing with running water were reduced by $26 \%$. Washing with $1 \%$ $\mathrm{H}_{2} \mathrm{O}_{2}$ solution reduced metalaxyl residues by $5 \%$, and the reduction after washing with both $2 \%$ baking soda and acetic acid were $2 \%$. The reduction levels for chlorpyrifos and diazinon were $33,29 \%$ with $1 \% \mathrm{H}_{2} \mathrm{O}_{2}$, $3,5 \%$ with baking soda, and $12,12 \%$ with $4 \%$ acetic acid. The less efficient removal of metalaxyl residues from orange by washing may be due to the distinct nature of orange peels, the high log Kow values of metalaxyl and its behavior as a systemic pesticide penetrating through the peel into the flesh. On the other hand, both chlorpyrifos and diazinon residues were eliminated from the orange more successfully as non-systemic pesticides, both physically (minor part) and chemically (major part).

Similar to our study, other investigations have shown that there were differences in efficacy of removing individual pesticides from fruits and vegetables by washing. Rani et al. (2013) reported that by washing of tomatoes with water, chlorpyrifos residues were reduced by 41 to $44 \%$ (Duirk and Collette, 2006). Wanwimolruk et al. (2017) reported on the effect of washing with running water on

Table 7. Physicochemical characteristics of pesticides metalaxyl, chlorpyrifos and diazinon.

\begin{tabular}{l|c|c|c|c|c|c}
\hline Pesticide & Category & Mode of action & $\begin{array}{c}\text { Molecular } \\
\text { Formula }\end{array}$ & $\begin{array}{c}\text { Mwt } \\
(\mathrm{g} / \mathrm{mol})\end{array}$ & $\begin{array}{c}\mathrm{SW} \\
(\mathrm{mg} / \mathrm{l})\end{array}$ & log Kow \\
\hline Metalaxyl & Fungicide & Systematic & $\mathrm{C}_{15} \mathrm{H}_{21} \mathrm{NO}_{4}$ & 279.33 & $\begin{array}{c}8.4 \\
\left.\text { (at } 22^{\circ} \mathrm{C}\right)\end{array}$ & 1.75 \\
Diazinon & $\begin{array}{c}\text { Insecticide, } \\
\text { Acaricide } \\
\text { Insecticide, } \\
\text { Acaricide, } \\
\text { (Cholinsterase } \\
\text { inhibition) }\end{array}$ & $\begin{array}{c}\text { Non-Systematic } \\
\text { Nematicide }\end{array}$ & $\mathrm{C}_{9} \mathrm{H}_{11} \mathrm{Cl}_{3} \mathrm{NO}_{3} \mathrm{PS}$ & 350.6 & $\begin{array}{c}1.4 \\
\left.\text { (at } 25^{\circ} \mathrm{C}\right)\end{array}$ & 4.70 \\
\hline
\end{tabular}

Sw: water solubility; Kow: Octanol-Water Partition Coefficient; Mwt: Molecular Weight 


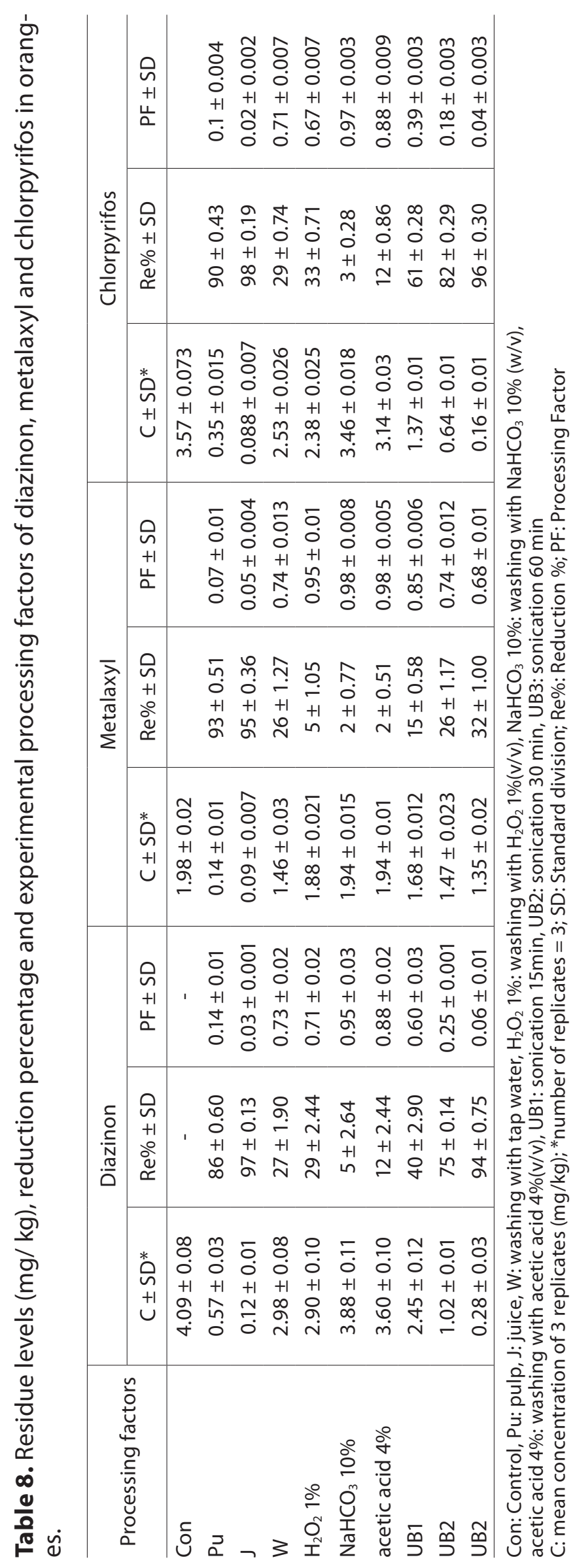


pesticide residue removal from tomatoes, in which both carbofuran and fenobucarb residues were reduced by $58 \%$ and $40 \%$, respectively, although without statistical significance ( $p>0.2)$. In the same study, cypermethrin and $\lambda$-cyhalothrin residues were removed by $27 \%$ by washing with running water although there was no significant difference ( $p>0.5$ ) between the mean concentrations of pesticides after washing vs. unwashed samples. In the study by Andrade et al. (2015) in cucumber, washing with water reduced the residues of procymidone by $24 \%$, while $85 \%$ was eliminated with the removal of the peel, even though this pesticide is systemic. Chlorpyrifos residues translocated into the internal tissue may not be removed physically and chemically (Pugliese et al., 2004). These disparities in efficacy of washing with water may be due to water solubility of pesticides.

Sonication in the ultrasonic bath was effective in eliminating pesticide residues in orange samples and sonication time (for 15 , 30 , and $60 \mathrm{~min}$ ) significantly influenced the effect. Sonication removed $98 \%$ and $94 \%$ of chlorpyrifos and diazinon residues, respectively, after 60 minutes, while the percentage of reduction reached $82 \%$ and $75 \%$ after $30 \mathrm{~min}$. Metalaxyl residues were eliminated by $32 \%$ after 60 minutes of sonication. Zhang et al. (2012) reported that sonication could effectively remove phorate residues in apple juice. Helmy et al. (2019) reported that sonication treatment effectively removed chlorpyrifos residues in tomato matrices, but not metalaxyl residues.

\section{Processing factors (PFs)}

The processing factors (PFs) for the household processes of oranges, which are necessary to refine the risk assessment of frequently detected pesticides, were lower than one. The lowest PFs were found in juicing $(0.05,0.02,0.03$ in metalaxyl, chlorpyrifos and diazinon, respectively) followed by sonication (0.04 and 0.06 , respectively in chlorpyrifos and diazinon). On the other hand, the highest PFs were found in the washing treatments for metalaxyl, ranging from 0.74 to 0.98 . The PFs for both chlorpyrifos and diazinon were lower than for metalaxyl in all treatments. The results are in agreement with those previously reported by Ramezani and Shahriari (2015) and Bajwa and Sandhu (2014). We conclude that the status of pesticide residues, mainly related to the physicochemical properties of the pesticides, affects their removal from oranges.

\section{Conclusion}

The tested QuEChERS and GC-MS method for the separation of metalaxyl, chlorpyrifos and diazinon in orange fruit was properly validated using orange samples and the results indicate that this method is specific, accurate and reproducible. The expanded uncertainty of the method is acceptable according to SANCO/12495/2011 guideline. The proposed method was also found to be suitable for different kind of orange fruits. The effects of different household processes indicated that the levels of metalaxyl, chlorpyrifos and diazinon residues can be reduced significantly by juicing, followed by peeling and sonication. The percentage reduction was lower in metalaxyl than in chlorpyrifos. The less efficient removal of metalaxyl residues from orange by washing may be due to the distinct nature of orange. All pesticides showed no matrix effect. The PF values for all treatments were lower than one, with the lowest for juicing, followed by sonication in all of pesticides. The household processes can substantially contribute to reduce consumer exposure to pesticides.

This study is heartily dedicated to Prof. Dr Ibrahim Abd El Salam Abd El Gawad who passed away before the completion of this work. The authors would like to acknowledge the experimental support of Food Safety and Quality Control laboratory, Faculty of Agriculture, Cairo University. 


\section{Literature Cited}

Abdel Ghani S.B., and Abdallah, O.I. 2016. Method validation and dissipation dynamics of chlorfenapyr in squash and okra. Food Chemistry, 194: 516-521.

Andrade, G.C., Monteiro, S.H., Francisco, J.G., Figueiredo, L.A., Rocha, A.A. and Tornisielo, V.L. 2015. Effects of types of washing and peeling in relation to pesticide residues in tomatoes. Journal of the Brazilian Chemical Society, 26(10): 1994-2002.

Bonnechère, A., Hanot, V., Jolie, R., Hendrickx, M., Bragard, C., Bedoret, T. and Van Loco, J. 2012. Processing Factors of Several Pesticides and Degradation Products in Carrots by Household and Industrial Processing. Journal of Food Research, 1(3): 68-83.

Bajwa, U. and Sandhu, K.S. 2014. Effect of Handling and Processing on Pesticide Residues in FoodA Review. Journal of Food Science and Technology, 52(2): 201-220.

Banerjee, K., Utture, S., Dasgupta, S., Kandaswamy, C., Pradhan, S., Kulkarni, S. and Adsule, P. 2012. Multiresidue determination of organic contaminants including pesticides, polychlorinated biphenyls, and polyaromatic hydrocarbons in fruits and vegetables by gas chromatographyetriple quadrupole mass spectrometry with introduction of semi quantification. Journal of Chromatography A, 270: 283.

Barros, H.R.M., Ferreira, T.A.P.C. and Genovese, M.I. 2012. Antioxidant capacity and mineral content of pulp and peel from commercial cultivars of citrus from Brazil. Food Chemistry, 134(4): 18921898.

Chawla, S., Patel, H.K., Gor, H.N., Vaghela, K.M., Solanki, P.P. and Shah, P.G. 2017. Evaluation of matrix effects in multiresidue analysis of pesticide residues in vegetables and spices by LC-MS/MS. Journal of AOAC International, 100(3): 616-623.

De Sousa, F.A., Guido Costa, A.I., De Queiroz, M.E.L.R., Teófilo, R.F., Neves, A.A. and De Pinho, G.P. 2012. Evaluation of matrix effect on the GC response of eleven pesticides by PCA. Food Chemistry, 135(1): 179-185.

Domínguez, A.M., Placencia, F., Cereceda, F., Fadic, X. and Quiroz, W. 2014. Analysis of tomato matrix effect in pesticide residue quantification through QuEChERS and single quadrupole GC/MS. Chilean Journal of Agricultural Research, 74(2): 148-156.

Duirk, S.E. and Collette T.W. 2006. Degradation of chlorpyrifos in aqueous chlorine solutions: Pathways, kinetics, and modeling. Environmental Science and Technology, 40: 546-51.

Ellison, S.R.L, Rosslein, M. and Williams, A. 2000. Editors. Quantifying uncertainty in analytical measurements. 3rd ed. EURACHEM/CITAC.

EN 15662: 2008. Foods of plant origin: Determina- tion of pesticide residues using GC-MS and/or LC-MS/MS following acetonitrile. Extraction/ partitioning and clean-up by dispersive SPE.

EU Commission. 2017. Guidance document on analytical quality control and validation procedures for pesticide residues analysis in food and feed. SANTE/11813/2017. European Commission health and Consumer Protection DirectorateGeneral, Brussels, Belgium.

Ferrer, C., Lozano, A., Agüera, A., Girón, A.J. and Fernández-Alba, A.R. 2011. Overcoming matrix effects using the dilution approach in multiresidue methods for fruits and vegetables. Journal of Chromatography A, 1218(42): 7634-7639.

Guedes J.A., Silva R.deO., Lima, C.G., Milhome, M.A. and do Nascimento R.F. 2016. Matrix effect in guava multiresidue analysis by QuEChERS method and gas chromatography coupled to quadrupole mass spectrometry. Food Chemistry, 199: 380-386.

González-Rodríguez, R.M., Rial-Otero, R, CanchoGrande B., Gonzalez-Barreiro, C. and Simal-Gándara, J. 2011. Review on the fate of pesticides during the processes within the food-production chain. Critical Reviews in Food Science and Nutrition, 51: 99-114.

Hassan, H., Elsayed, E., El-Raouf, A.E.R.A. and Salman, S.N. 2019. Method validation and evaluation of household processing on reduction of pesticide residues in tomato. Journal fur Verbraucherschutz und Lebensmittelsicherheit. 14(1): 31-39.

Iñigo-Nuñez, S., Herreros, M.A., Encinas, T., and Gonzalez-Bulnes, A. 2010. Estimated daily intake of pesticides and xenoestrogenic exposure by fruit consumption in the female population from a Mediterranean country (Spain). Food Control, 21(4): 471-477.

Jardim, A.N.O. and Caldas, E.D. 2012. Brazilian monitoring programs for pesticide residues in food Results from 2001 to 2010. Food Control, 25(2): 607-616.

Jiang, Y., Shibamoto, T., Li, Y. and Pan, C. 2013. Effect of household and commercial processing on acetamiprid, azoxystrobin and methidathion residues during crude rapeseed oil production. Food Additives and Contaminants: Part A, 30(7): $1279 \mathrm{e} 1286$.

Knezevic, Z., Serdar, M. and Ahel, M. 2012. Risk assessment of the intake of pesticides in Croatian diet. Food Control, 23(1): 59-65.

Kwon, H., Lehotay S.J. and Geis-Asteggiante L. 2012. Variability of matrix effects in liquid and gas chromatography-mass spectrometry analysis of pesticide residues after QuEChERS sample preparation of different food crops. Journal of Chromatography A, 1270: 235-45.

Ling, Y., Wang, H., Yong, W., Zhang, F., Sun, L., Yang, M. and Chu, X. 2011. The effects of washing and cooking on chlorpyrifos and its toxic metabo- 
lites in vegetables. Food Control, 22(1), 54-58.

Lozowicka, B., Jankowska, M., Hrynko, I. and Kaczynski, P. 2016. Removal of 16 pesticide residues from strawberries by washing with tap and ozone water, ultrasonic cleaning and boiling. Environmental Monitoring and Assessment, 188: 1-19.

Malhat, F., Boulangé, J., Abdelraheem, E., Abd Allah, O., Abd El-Hamid, R. and Abd El-Salam, S. 2017. Validation of QuEChERS based method for determination of fenitrothion residues in tomatoes by gas chromatography-flame photometric detector: Decline pattern and risk assessment. Food Chemistry. 229: 814-819.

Pano-Farias, N.S., Ceballos-Magaña, S.G., Muñiz-Valencia, R. and Gonzalez, J. 2017. Validation and assessment of matrix effect and uncertainty of a gas chromatography coupled to mass spectrometry method for pesticides in papaya and avocado samples. Journal of Food and Drug Analysis, 25(3): 501-509.

Polat, B. and Tiryaki, O. 2019. Assessing washing methods for reduction of pesticide residues in Capia pepper with LC-MS / MS. Journal of Environmental Science and Health, Part B, 55(1): 1-10.

Pugliese, P., Moltó, J.C., Damiani, P., Marín, R., Cossignani, L. and Mañes, J. 2004. Gas chromatographic evaluation of pesticide residue contents in nectarines after non-toxic washing treatments. Journal of Chromatography A. 1050(2): 185-191.

Ramezani, M.K. and Shahriari, D. 2014. Dissipation behavior, processing factors and risk assessment for metalaxyl in greenhouse-grown cucumber. Pest Management Science, 71(4): 579583.

Rani, M., Saini, S. and Kumari, B. 2013. Persistence and effect of processing on chlorpyriphos residues in tomato (Lycopersicon esculantum Mill.). Ecotoxicology and Environmental Safety, 95: 247252.

Reiler, E., Jørs, E., Bælum, J., Huici, O., Alvarez Caero, M.M. and Cedergreen, N. 2015. The influence of tomato processing on residues of organochlorine and organophosphate insecticides and their associated dietary risk. Science of the Total Environment, 6(2): 262-269.
SANCO Document /12571/2013. Guidance document on analytical quality control and validation procedures for pesticide residues analysis in food and feed. <http://www.eurl-pesticides. eu/library/docs/allcrl/AqcGuidance_Sanco_ 2013_12571.pdf>

Timme, G. and Walz-Tylla, B. 2004. Effects of food preparation and processing on pesticide residues in commodities of plant origin. In Pesticides residues in food and drinking water: human exposure and risks. 121-148.

Tomer, V. and Sangha, J.K. 2013. Vegetable processing at household level: Effective tool against pesticide residue exposure. Toxicology and Food Technology, 6(2): 43-53.

Wanwimolruk, S., Duangsuwan, W., Phopin, K., Boonpangrak, S. 2017. Food safety in Thailand 5: the effect of washing pesticide residues found in cabbages and tomatoes. Journal of Consumer Protection and Food Safety, 12:209-221

Xu, W., Li, H., Guan, Q., Shen, Y., and Cheng, L. 2017. A rapid and simple liquid chromatography-tandem mass spectrometry method for the measurement of testosterone, androstenedione, and dehydroepiandrosterone in human serum. Journal of Clinical Laboratory Analysis, 31(5), e22102.

Zhang, Y., Zhang, Z., Chen, F., Zhang, H., Hu, X. 2012. Effect of sonication on eliminating of phorate in apple juice. Ultrasonics Sonochemistry, 19: 4348. doi:10.1016/j.ultsonch.2011.05.014

Zhao, L. and Mao, D. 2011. "Analysis of Pesticides in Food by GC/MS/MS using the Ultra Inert Liner with Wool" Application note, Agilent Technologies, Inc., Publication number 5990-7706 EN.

Zhao, L. 2013. Evaluating Inert Flow Path Components and Entire Flow Path for GC/MS/MS Pesticide Analysis. Application note, Agilent Technologies, Inc.

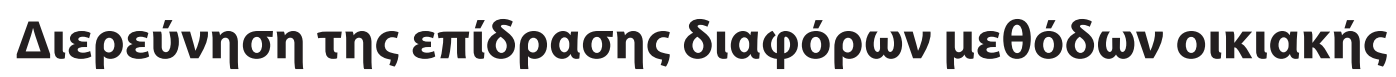

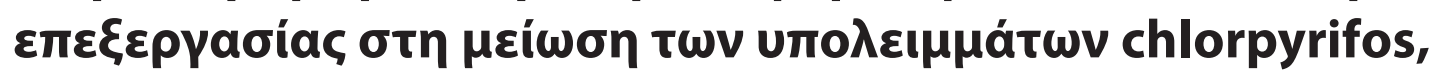

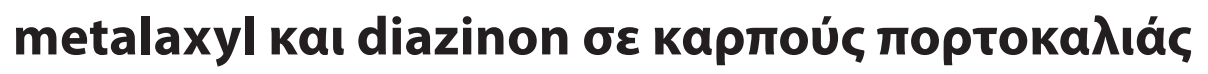

\author{
E. El-Sayed, H. Hassan, A. Abd El-Raouf and S.N. Salman
}

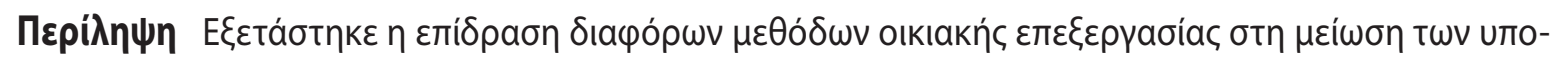

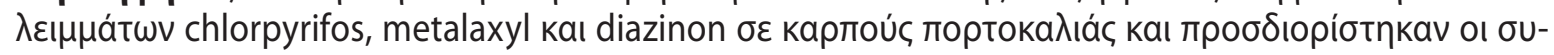




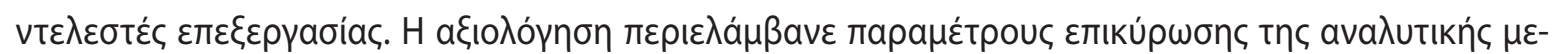

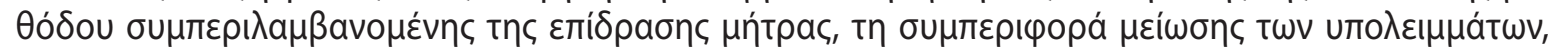

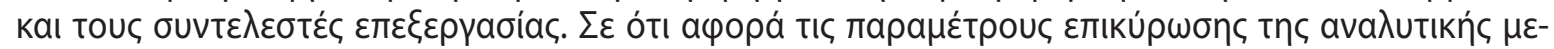

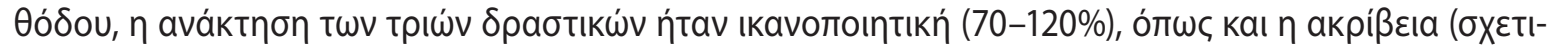

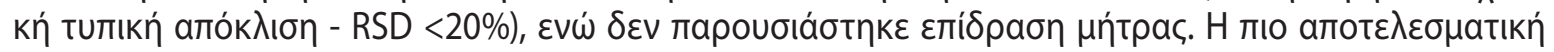

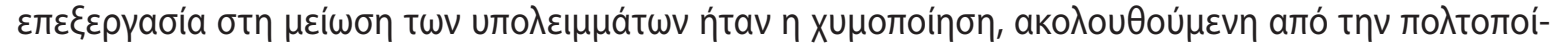

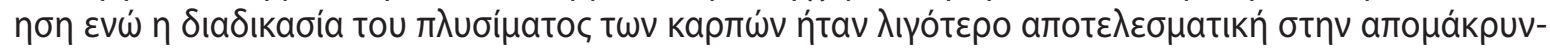

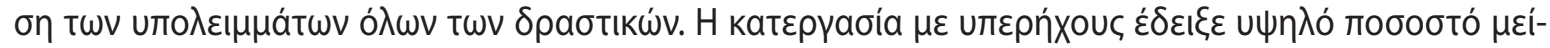

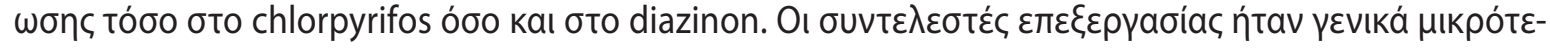

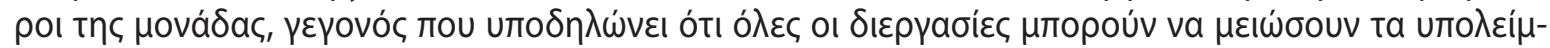

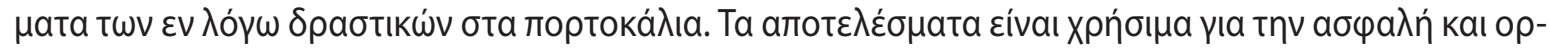

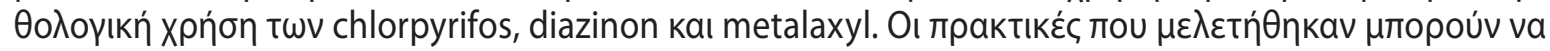

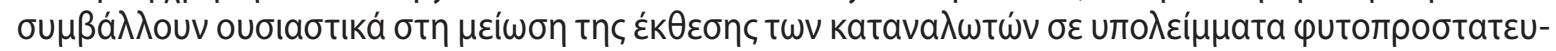

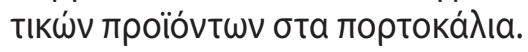

Hellenic Plant Protection Journal 14: 65-76, 2021 